\title{
Clinicopathological features, treatment patterns, and prognosis of squamous cell carcinoma of the breast: an NCDB analysis
}

Liling Zhu ${ }^{2,3^{*}}$ and Kai Chen ${ }^{1,2^{*}}$ (D)

\begin{abstract}
Background: Squamous cell carcinoma (SCC) of the breast is a rare malignancy. The clinicopathological features, treatment patterns and prognosis of SCC of the breast is still unclear.

Methods: In this study, we performed a 1:4 SCC-IDC (infiltrating ductal carcinoma) matching analysis of patients diagnosed between 2004 and 2014, using the data from the national cancer database. We used Chi-square test to compare the clinicopathological features and treatment patterns between SCC $(n=686)$ and IDC $(n=2744)$ patients. We used Kaplan-Meier analysis and Cox-regression to estimate the survival of SCC and IDC patients.

Results: We observed that SCC patients are more likely to have T3-4, grade III, and ER negative diseases, when compared to IDC patients. Breast conserving surgery (BCS) (58.3\% vs $65.4 \%, p=0.048)$, as well as radiotherapy after BCS (65.3\% vs. $83.0 \%, p<0.001)$, was less performed in SCC patients. Among low-risk patients, chemotherapy was used more often for SCC patients (42.9\%) than for IDC (18.7\%) patients $(p=0.002)$. In HR-positive patients, endocrine therapy was used less often for SCC patients (51.6\%) than for IDC patients (70.5\%) $(p<0.001)$. SCC (vs. IDC) was associated with no responses to neoadjuvant chemotherapy ( $20 \%$ vs. $5.05 \%, p=0.019)$. Adjusted analysis confirmed that SCC (vs. IDC) was associated with worse OS ( $H R=1.40,95 \% \mathrm{Cl} 1.17-1.67, P<0.01)$, after a median followup of 58.3 months. In SCC patients, HR status is not prognostic of OS, but endocrine therapy was significantly associated with improved OS in HR-positive SCC patients.
\end{abstract}

Conclusions: We conclude that SCC is associated with poorer clinicopathological features, no responses to neoadjuvant chemotherapy and worse clinical outcomes than IDC. The treatment patterns for SCC and IDC are different. Endocrine therapy is necessary for HR-positive SCC patients.

Keywords: Breast cancer, Squamous cell carcinoma, Infiltrating ductal carcinoma, Survival, Endocrine therapy, Chemotherapy

\section{Background}

Squamous cell carcinoma (SCC) of the breast is a rare malignancy that accounts for $<0.2 \%$ of all breast cancers [1]. Diagnosis of SCC can be made when a predominance $(>90 \%)$ of areas with squamous cells is noticed at histology examinations [2]. The origin of the SCC

\footnotetext{
* Correspondence: zhuliling@mail.sysu.edu.cn; liling.zhu@yale.edu; chenkai23@mail.sysu.edu.cn

${ }^{2}$ Department of Breast Surgery, Breast Tumor Center, Sun Yat-sen Memorial Hospital, Sun Yat-sen University, 107 Yanjiang West. Road, Guangzhou 510120, People's Republic of China

${ }^{1}$ Guangdong Provincial Key Laboratory of Malignant Tumor Epigenetics and Gene Regulation, Sun Yat-Sen Memorial Hospital, Sun Yat-Sen University, Guangzhou, Guangdong, China

Full list of author information is available at the end of the article
}

component is still an unanswered question. A recent study [3] showed that SCC and its adjacent infiltrating ductal carcinoma (IDC) component shared the same origin, but their transcription landscape [4] and drivenpathways [5] are different. Thus, whether the differing histology of SCC may result in different biological behavior, different treatment patterns and prognosis is not clear. Most of the studies [1, 6] are limited significantly by their small sample size, due to its rarity. Therefore, a national cancer database remains as the only choice to provide adequate sample size to investigate SCC of the breast.

(c) The Author(s). 2019 Open Access This article is distributed under the terms of the Creative Commons Attribution 4.0 International License (http://creativecommons.org/licenses/by/4.0/), which permits unrestricted use, distribution, and 
The national cancer database (NCDB) is a hospitalbased database that covers approximately $70 \%$ of cancer patients in the United States [7]. The participating centers are required to submit data to the database. In this study, we used the NCDB to compare the clinicopathological features, treatment patterns and prognoses of IDC and SCC patients. We hypothesized that SCC (vs. IDC) was associated with poor clinicopathological characteristics, different treatment patterns, and worse survival. We also performed an exploratory analysis of the benefits of systemic therapies for SCC patients.

\section{Methods}

We searched the NCDB for eligible patients using the inclusion and exclusion criteria below:

\section{Inclusion}

1) Female patients with pathologically confirmed breast cancer,

2) Patients who were diagnosed between 2004 and 2014, and

3) Diagnoses of SCC of the breast (code 8070-8078), and IDC (code 8500).

\section{Exclusion criteria}

1) Patients with prior diagnoses of malignant tumors and

2) A number of follow-up months equal to 0 .

A total of 686 SCC patients and 1,211,403 IDC patients were identified from the database. Given the huge discrepancy of the amount of the SCC and IDC patients, we performed a 1:4 SCC-IDC matching on the following factors: Year of diagnosis (2004-2014), Facility type (Community Cancer Program, Comprehensive Community Cancer Program, Academic/Research Program, Integrated Network Cancer Program, Unknown), Facility location (New England, Middle Atlantic, South Atlantic, East North Central, East South Central, West North Central, West South Central, Mountain, Pacific), city type (Metropolitan, Nonmetropolitan/Unknown), type of insurance (Not insured, Private insurance, Medicaid, Medicare, other Government, Unknown.). There were 686 SCC and 2744 IDC patients being selected as the final cohort for analysis. This study was an epidemiological study using de-identified data from the NCDB database. Therefore, consent for patient participation and study publication was not required. The study approval was waived by the ethical committee of Yale University and Sun Yat-sen Memorial Hospital.

The following data were collected for each patient: the year of diagnosis, age, race, Charlson-Deyo score, tumor grade, lymphovascular invasion, $\mathrm{T}$-stage, $\mathrm{N}$-stage, histology, estrogen receptor (ER) status, progesterone receptor (PR) status, HER2 status, primary surgery categorization, radiation therapy (RT), chemotherapy, neoadjuvant chemotherapy, response to chemotherapy, endocrine therapy, survival month and OS status. Patients were categorized into three age groups based on their ages at diagnosis ( $\leq 50$ yrs., 50 60 yrs., $>60$ yrs). We used this cut-off because the median age was close to 60 yrs. in our study population and because 50 yrs. is the usual cut-off age for premenopausal and post-menopausal women. Histology was divided into two categories, namely, IDC and SCC.

\section{Statistical analysis}

We conducted a descriptive analysis of the baseline clinicopathological features of the included patients and used the Chi-square test to compare the characteristics of the patients with different histologies. The median follow-up time was calculated as the median observed survival time of the entire population. OS was measured as the time from diagnosis to death due to any cause. The cumulative OS rates were estimated using KaplanMeier analysis. We used a Cox regression model to screen for prognostic factors of OS. We tested the proportional hazards assumption by plotting the scaled Schoenfeld residuals of all coefficients over time and found no violations. All $P$-values were two-sided. $P$ values less than 0.05 were considered statistically significant. Statistical analysis was performed using Stata/MP, version 13.0 (StataCorp LP, College Station, TX, USA).

\section{Results}

A total of 3430 patients (IDC: 2744; SCC: 686), with a median age of 61 years, were included in this study. The clinicopathological features are listed in Table 1. In general, SCC is associated with poorer clinicopathological features. A total of $23.1 \%$ of the SCC patients had T3-4 disease, whereas only $4 \%$ of the IDC patients had T3-4 disease. The proportions of grade III disease were 61.06 and $39.10 \%$ for the SCC and IDC patients, respectively. Additionally, the proportions of ER-negative tumors were 74.91 and 21.95\% for the SCC and IDC patients, respectively. The distribution of N-stage was similar between SCC and IDC patients.

\section{Different treatment patterns between SCC and IDC patients} In patients with T1-2 stages who did not received neoadjuvant chemotherapy, there were $58.3 \%(120 / 206)$ vs. $65.4 \%(890 / 1362)$ of the SCC and IDC patients received BCS $(P=0.048)$ respectively. Among the patients with BCS $(N=1791,16$ patients with unknown RT status were excluded.), 65.3 and $83.0 \%$ of the SCC and IDC patients received RT $(P<0.01)$, respectively. The use of RT in node-positive patients with mastectomies, were similar in SCC and IDC patients (42.1\% (37/88) vs. $48.4 \%(166 / 343)$, $P=0.287)$. 
Table 1 Clinicopathological features of study population

\begin{tabular}{|c|c|c|c|c|c|}
\hline & \multicolumn{4}{|c|}{ Histology } & \multirow[t]{3}{*}{$P$} \\
\hline & \multicolumn{2}{|c|}{ Infiltrating Ductal Carcinoma } & \multicolumn{2}{|c|}{ Squamous Cell Carcinoma } & \\
\hline & $\bar{N}$ & $\%^{a}$ & $\mathrm{~N}$ & $\%^{a}$ & \\
\hline \multicolumn{6}{|l|}{ Race } \\
\hline White & 2259 & 83.33 & 540 & 79.65 & \multirow[t]{4}{*}{$<0.01$} \\
\hline African American & 343 & 12.65 & 119 & 17.55 & \\
\hline Others & 109 & 4.02 & 19 & 2.80 & \\
\hline Unknown & 33 & & 8 & & \\
\hline \multicolumn{6}{|l|}{ Charlson-Deyo Score } \\
\hline 0 & 2346 & 85.50 & 555 & 80.90 & \multirow[t]{4}{*}{0.02} \\
\hline 1 & 328 & 11.95 & 104 & 15.16 & \\
\hline 2 & 54 & 1.97 & 20 & 2.92 & \\
\hline 3 & 16 & 0.58 & 7 & 1.02 & \\
\hline \multicolumn{6}{|l|}{ Grade } \\
\hline । & 476 & 18.90 & 62 & 11.33 & \multirow[t]{4}{*}{$<0.01$} \\
\hline$\|$ & 1058 & 42.00 & 151 & 27.61 & \\
\hline III & 985 & 39.10 & 334 & 61.06 & \\
\hline Unknown/IV & 225 & & 139 & & \\
\hline \multicolumn{6}{|c|}{ Lymphovascular Invasion } \\
\hline Absence & 768 & 79.67 & 185 & 85.65 & \multirow[t]{3}{*}{0.04} \\
\hline Present & 196 & 20.33 & 31 & 14.35 & \\
\hline Not Applicable & 1780 & & 470 & & \\
\hline \multicolumn{6}{|l|}{ T-Stage } \\
\hline T0-T1 & 1441 & 52.51 & 145 & 21.14 & \multirow[t]{5}{*}{$<0.01$} \\
\hline $\mathrm{T} 2$ & 502 & 18.29 & 178 & 25.95 & \\
\hline T3 & 67 & 2.44 & 100 & 14.58 & \\
\hline $\mathrm{T} 4$ & 45 & 1.64 & 58 & 8.45 & \\
\hline Tx & 689 & 25.11 & 205 & 29.88 & \\
\hline \multicolumn{6}{|l|}{ N-Stage } \\
\hline No & 1373 & 50.04 & 331 & 48.25 & \multirow[t]{5}{*}{0.228} \\
\hline N1 & 381 & 13.88 & 85 & 12.39 & \\
\hline N2 & 115 & 4.19 & 22 & 3.21 & \\
\hline N3 & 56 & 2.04 & 16 & 2.33 & \\
\hline$N x$ & 819 & 29.85 & 232 & 33.82 & \\
\hline \multicolumn{6}{|l|}{ M-Stage } \\
\hline MO & 2250 & 82.00 & 490 & 71.43 & \multirow[t]{3}{*}{$<0.01$} \\
\hline M1 & 49 & 1.79 & 23 & 3.35 & \\
\hline$M x$ & 445 & 16.22 & 173 & 25.22 & \\
\hline \multicolumn{6}{|l|}{ Estrogen Receptor } \\
\hline Negative & 569 & 21.95 & 421 & 74.91 & \multirow[t]{3}{*}{$<0.01$} \\
\hline Positive & 2023 & 78.05 & 141 & 25.09 & \\
\hline Unknown & 152 & & 124 & & \\
\hline \multicolumn{6}{|c|}{ Progesterone Receptor } \\
\hline Negative & 843 & 32.69 & 491 & 87.84 & \multirow[t]{2}{*}{$<0.01$} \\
\hline Positive & 1736 & 67.31 & 68 & 12.16 & \\
\hline
\end{tabular}


Table 1 Clinicopathological features of study population (Continued)

\begin{tabular}{|c|c|c|c|c|c|}
\hline & \multicolumn{4}{|c|}{ Histology } & \multirow[t]{3}{*}{$P$} \\
\hline & \multicolumn{2}{|c|}{ Infiltrating Ductal Carcinoma } & \multicolumn{2}{|c|}{ Squamous Cell Carcinoma } & \\
\hline & $\bar{N}$ & $\%^{a}$ & $\bar{N}$ & $\%^{a}$ & \\
\hline Unknown & 165 & & 127 & & \\
\hline \multicolumn{6}{|l|}{$\mathrm{HER} 2^{\mathrm{b}}$} \\
\hline Negative & 829 & 78.2 & 207 & 87.7 & $<0.01$ \\
\hline Borderline & 31 & 2.9 & 2 & 0.9 & \\
\hline Positive & 200 & 18.9 & 27 & 11.4 & \\
\hline Unknown & 156 & & 68 & & \\
\hline \multicolumn{6}{|l|}{ Breast Surgery } \\
\hline No_Surgery & 167 & 6.10 & 90 & 13.16 & $<0.01$ \\
\hline Breast-conserving surgery & 1561 & 56.99 & 246 & 35.96 & \\
\hline Mastectomy & 1010 & 36.87 & 348 & 50.88 & \\
\hline Surgery (Types_Unknown) & 1 & 0.04 & 0 & 0.00 & \\
\hline Unknown & 5 & & 2 & & \\
\hline \multicolumn{6}{|l|}{ Radiation Therapy } \\
\hline No & 1119 & 41.23 & 373 & 54.93 & $<0.01$ \\
\hline Yes & 1595 & 58.77 & 306 & 45.07 & \\
\hline Unknown & 30 & & 7 & & \\
\hline \multicolumn{6}{|l|}{ Chemotherapy } \\
\hline None & 1506 & 58.28 & 294 & 46.08 & $<0.01$ \\
\hline Single-Agent Chemotherapy & 44 & 1.70 & 23 & 3.61 & \\
\hline Multiagent Chemotherapy & 1034 & 40.02 & 321 & 50.31 & \\
\hline Unknown & 160 & & 48 & & \\
\hline \multicolumn{6}{|l|}{ Neoadjuvant chemotherapy } \\
\hline No & 1884 & 89.89 & 447 & 83.86 & $<0.01$ \\
\hline Yes & 212 & 10.11 & 86 & 16.14 & \\
\hline Unknown & 91 & & 14 & & \\
\hline \multicolumn{6}{|l|}{ Endocrine Therapy } \\
\hline No & 1110 & 42.53 & 567 & 85.91 & $<0.01$ \\
\hline Yes & 1500 & 57.47 & 93 & 14.09 & \\
\hline Unknown & 134 & & 26 & & \\
\hline
\end{tabular}

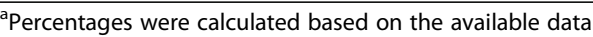

bonly patients after 2010 were used for analysis of HER2 status

In patients with favorable prognosis (hormone receptor (HR)-positive, HER2-negative and node-negative), chemotherapy was performed in $42.9 \%(12 / 28)$ and $18.7 \%$ $(80 / 427)$ of the SCC and IDC patients, respectively $(P=0.002)$. In the HR-positive, node-negative patients who were diagnosed before 2010 (when the HER2 status was unknown), there were $51.6 \%(32 / 62)$ and $24.9 \%(248 / 997)$ of the SCC and IDC patients who had received chemotherapy, respectively $(P<0.001)$. Among the patients with HR-positive disease, endocrine therapy was performed in $51.6 \%(79 / 153)$ and $70.5 \%(1446 / 2050)$ of the SCC and IDC patients, respectively $(P<0.001)$.

\section{Response to neoadjuvant chemotherapy}

In this study, there were 298 patients with known history of neoadjuvant chemotherapy, and 129 of them had clear information about treatment responses (CR, PR, CR/PR, No response). SCC (vs. IDC) was significantly associated with no responses to neoadjuvant chemotherapy $(20 \%$ vs. $5.05 \%, P=0.019)$ (Table 2$)$.

\section{Survival analysis}

With a median follow-up time of 58.3 months, the respective 5 -yr and 10 -yr OS were 62.1 and $50.6 \%$ for the SCC patients, and 83.0 and $69.5 \%$ for the IDC patients, respectively $(P<0.001)$. SCC (vs. IDC) was associated 
Table 2 Response to neoadjuvant chemotherapy by histology

\begin{tabular}{|c|c|c|c|c|c|c|c|c|c|}
\hline \multicolumn{10}{|l|}{ Category 1} \\
\hline \multirow[t]{2}{*}{ Histology } & \multicolumn{2}{|l|}{$C R$} & \multicolumn{2}{|c|}{$\mathrm{PR}, \mathrm{CR} / \mathrm{PR}$} & \multicolumn{2}{|c|}{ No response } & \multicolumn{2}{|c|}{ Total } & $P^{*}$ \\
\hline & $\mathrm{N}$ & $\%$ & N & $\%$ & $\mathrm{~N}$ & $\%$ & $\mathrm{~N}$ & $\%$ & \\
\hline IDC & 35 & 35.35 & 59 & 59.6 & 5 & 5.05 & 99 & 100 & 0.042 \\
\hline SCC & 8 & 26.67 & 16 & 53.33 & 6 & 20 & 30 & 100 & \\
\hline \multicolumn{10}{|l|}{ Category 2} \\
\hline \multirow[t]{2}{*}{ Histology } & \multicolumn{4}{|c|}{ Response (CR, PR, CR/PR) } & \multicolumn{2}{|c|}{ No response } & \multicolumn{2}{|c|}{ Total } & $p^{*}$ \\
\hline & $\mathrm{N}$ & & $\%$ & & $\mathrm{~N}$ & $\%$ & $\mathrm{~N}$ & $\%$ & \\
\hline IDC & 94 & & 94.9 & & 5 & 5.05 & 99 & 100 & 0.019 \\
\hline SCC & 24 & & 80 & & 6 & 20 & 30 & 100 & \\
\hline
\end{tabular}

$C R$ Complete Response, $P R$ Partial Response, IDC Infiltrating Ductal Carcinoma, SCC Squamous Cell Carcinoma

${ }^{*}$ Fisher Exact test

with poorer $\mathrm{OS}$ in univariate analysis $(\mathrm{HR}=2.39,95 \% \mathrm{CI}$ 2.06-2.77, $P<0.001)$, and in multivariate $(\mathrm{HR}=1.40$, $95 \%$ CI 1.17-1.67, $P<0.001)$ analysis after adjusting for age, race, comorbidity, T-stage, $\mathrm{N}$-stage, $\mathrm{M}$-stage, ER, PR, tumor grade, LVI, surgery, endocrine therapy, chemotherapy and RT (Table 3, \& Additional file 1: Figure S1). In patients who were diagnosed after 2010, SCC (vs. IDC) was still associated with poorer OS (HR $=1.57,95 \% \mathrm{CI} 1.11-$ $2.21, P=0.011$ ), after adjusting for the above variables, as well as LVI and HER2 status.

We hypothesized that there was interaction between hormonal status (positive vs. negative) and the histology (SCC vs. IDC) in the analysis of OS. We performed a subgroup analysis and noticed that positive (vs. negative) hormonal status was significantly associated with improved OS in IDC $(P<0.01)$ patients, but not in the SCC $(P=0.042)$ patients (Fig. 1, Interaction test, $P=0.023)$. However, endocrine therapy was also associated with improved OS for the HR-positive IDC patients $(\mathrm{HR}=0.61$, 95\%CI 0.48-0.77, $P<0.001$ ), as well as for the HR-positive SCC patients $(\mathrm{HR}=0.30,95 \% \mathrm{CI} 0.15-0.59, P<0.001)$ (Fig. 2), after adjusting for age, race, comorbidity score, grade, T-stage, $\mathrm{N}$-stage, $\mathrm{M}$-stage, and chemotherapy.

\section{Discussion}

\section{Prognosis of SCC patients}

Previous studies have shown that SCC of the breast is more likely to be HR-negative and is associated with worse clinical outcomes [2, 8, 9]. Hennessy et al. [2] reported that the 5-year overall survival (OS) rates of 33 and 137 SCC patients selected from the M.D. Anderson Cancer Center and the SEER database, respectively, were 40 and $64 \%$, respectively. In an update, Yadav et al [9] reported a 5 -year cancer-specific survival rate of $63.5 \%$ for 445 SCC patients who were collected from the SEER database. Due to the rarity of SCC, only the data from the national cancer database is able to provide adequate statistical power to study the prognosis of SCC. However, several important prognostic factors, and the information of adjuvant therapies were lacking in the SEER database. In contrast, the NCDB database provides more prognostic factors (e.g comorbidity score, HER2 status and LVI status), as well as the information of adjuvant therapies (chemotherapy and endocrine therapy), therefore allows a more accurate estimation with less bias. In this study, we observed that the SCC patients had poorer clinicopathological features (e.g., T3-4, grade III, HR-negative disease) than the IDC patients. The adjusted analysis demonstrated that the SCC patients had significantly worse clinical outcomes than the IDC patients in both the 2004-2014 and 2010-2014 (HER2 status adjusted) cohorts. In consistent with previous studies, we confirmed that SCC (vs. IDC) is associated with poorer OS, after adjusting for more prognostic factors and adjuvant therapies.

\section{SCC \& systemic therapies}

The concept that SCC has worse clinical outcomes than IDC is likely to affect the choice of treatments in the clinical practices. This is confirmed in our study that chemotherapy was more prevalent in low-risk $(\mathrm{HR}+1$ HER2-/LN-) SCC (vs. IDC) patients (42.9\% vs. $18.7 \%$, $P=0.002$ ). However, whether the SCC is responsive to chemotherapy is still unknown. Hennessy et al. [2] and Zhang et al. [6] reported that they used no responses were observed in their SCC patients after neoadjuvant chemotherapy. Only two case-reports [10, 11] have suggested that cisplatin-based chemotherapy is able to achieve long-term control, but these results need further verification. In our study, we noticed that SCC (vs. IDC) was significantly associated with no responses to neoadjuvant chemotherapy $(20 \%$ vs. $5.05 \%, P=0.019)$. Therefore, the benefit of chemotherapy in SCC patients remains unknown.

In this study, we observed that the endocrine therapy was less performed in the HR-positive SCC (51.6\%) patients, than in the HR-positive IDC (70.5\%) patients. A contributing reason could be that endocrine therapy in the head \& neck or esophageal SCC patients is not useful in clinical practices $[12,13]$, even if the in vitro evidences $[14,15]$ had suggested the role of tamoxifen for SCC of the oral cavity or esophagus. However, SCC of the breast might possibly be different from the head \& neck SCC. A recent study used whole-exome sequencing to show that the SCC components have nearly identical landscapes of somatic mutations to their adjacent IDC component, suggesting that SCC may originate from the IDC [3]. Since the role of endocrine therapy had been established in IDC patients, it is possible the endocrine therapy would also be beneficial in SCC patients. In the analysis of prognostic factors of OS, we observed a significant interaction between the HR status and the histology (SCC vs. IDC). The HR status was prognostic only 
Table 3 Univariate and multivariate analysis of prognostic factors of OS

\begin{tabular}{|c|c|c|c|c|}
\hline \multirow[t]{2}{*}{ Variables } & \multicolumn{2}{|l|}{ Univariate analysis } & \multicolumn{2}{|c|}{ Multivariate analysis } \\
\hline & $\overline{\mathrm{HR}(95 \% \mathrm{Cl})}$ & $P$ & $\overline{\mathrm{HR}(95 \% \mathrm{Cl})}$ & $P$ \\
\hline \multicolumn{5}{|l|}{ Age } \\
\hline$<=50$ & 1 & & 1 & \\
\hline $50-60$ & $1.13(0.89-1.44)$ & 0.301 & $1.10(0.86-1.40)$ & 0.445 \\
\hline$>60$ & $2.25(1.86-2.74)$ & $<0.001$ & $2.11(1.72-2.60)$ & $<0.001$ \\
\hline \multicolumn{5}{|l|}{ Race } \\
\hline White & 1 & & 1 & \\
\hline African American & $1.51(1.26-1.80)$ & $<0.001$ & $1.05(0.87-1.27)$ & 0.576 \\
\hline Others & $0.43(0.24-0.77)$ & 0.004 & $0.48(0.27-0.85)$ & 0.012 \\
\hline Unknown & $0.53(0.24-1.19)$ & 0.126 & $0.49(0.22-1.10)$ & 0.082 \\
\hline \multicolumn{5}{|l|}{ Comorbidity score } \\
\hline Score 0 & 1 & & 1 & \\
\hline Score 1 & $2.17(1.85-2.54)$ & $<0.001$ & $1.65(1.40-1.95)$ & $<0.001$ \\
\hline \multicolumn{5}{|l|}{ Grade } \\
\hline I & 1 & & 1 & \\
\hline$\|$ & $1.20(0.94-1.54)$ & 0.149 & $0.98(0.76-1.26)$ & 0.877 \\
\hline III & $2.05(1.62-2.58)$ & $<0.001$ & $1.35(1.05-1.74)$ & 0.02 \\
\hline Unknown/IV & $1.86(1.39-2.49)$ & $<0.001$ & $1.05(0.77-1.42)$ & 0.767 \\
\hline \multicolumn{5}{|l|}{ T-stage } \\
\hline T0-T1 & 1 & & 1 & \\
\hline $\mathrm{T} 2$ & $2.24(1.86-2.69)$ & $<0.001$ & $1.65(1.35-2.03)$ & $<0.001$ \\
\hline T3-4 & $5.63(4.60-6.90)$ & $<0.001$ & $2.75(2.14-3.55)$ & $<0.001$ \\
\hline Tx & $1.25(1.04-1.51)$ & 0.017 & $0.62(0.45-0.85)$ & 0.003 \\
\hline \multicolumn{5}{|l|}{$\mathrm{N}$-stage } \\
\hline No & 1 & & 1 & \\
\hline N1 & $1.82(1.49-2.22)$ & $<0.001$ & $1.77(1.43-2.18)$ & $<0.001$ \\
\hline N2-3 & $3.61(2.90-4.49)$ & $<0.001$ & $2.18(1.69-2.83)$ & $<0.001$ \\
\hline Nx & $1.12(0.94-1.32)$ & 0.197 & $0.95(0.70-1.30)$ & 0.764 \\
\hline \multicolumn{5}{|l|}{ M-stage } \\
\hline Mo & 1 & & 1 & \\
\hline M1 & $8.47(6.42-11.17)$ & $<0.001$ & $4.50(3.29-6.16)$ & $<0.001$ \\
\hline$M x$ & $2.04(1.74-2.39)$ & $<0.001$ & $1.90(1.53-2.36)$ & $<0.001$ \\
\hline \multicolumn{5}{|l|}{ Histology } \\
\hline Infiltrating Ductal Carcinoma & 1 & & 1 & \\
\hline Squamous Cell Carcinoma & $2.39(2.06-2.77)$ & $<0.001$ & $1.37(1.15-1.64)$ & $<0.001$ \\
\hline \multicolumn{5}{|l|}{ Lymphovascular invasion $^{a}$} \\
\hline Absence & 1 & & Not included & \\
\hline Presence & $1.91(1.37-2.67)$ & $<0.001$ & & \\
\hline Not applicable/Unknown & $2.18(1.63-2.91)$ & $<0.001$ & & \\
\hline \multicolumn{5}{|l|}{ Estrogen Receptor } \\
\hline Negative & 1 & & 1 & \\
\hline Positive & $0.53(0.46-0.61)$ & $<0.001$ & $0.86(0.67-1.10)$ & 0.218 \\
\hline Unknown & $0.85(0.67-1.08)$ & 0.195 & $2.46(0.60-10.15)$ & 0.212 \\
\hline
\end{tabular}

Progesterone Receptor 
Table 3 Univariate and multivariate analysis of prognostic factors of OS (Continued)

\begin{tabular}{|c|c|c|c|c|}
\hline \multirow[t]{2}{*}{ Variables } & \multicolumn{2}{|l|}{ Univariate analysis } & \multicolumn{2}{|c|}{ Multivariate analysis } \\
\hline & $\mathrm{HR}(95 \% \mathrm{Cl})$ & $P$ & $\mathrm{HR}(95 \% \mathrm{Cl})$ & $P$ \\
\hline Negative & 1 & & 1 & \\
\hline Positive & $0.56(0.48-0.65)$ & $<0.001$ & $0.96(0.76-1.20)$ & 0.724 \\
\hline Unknown & $0.92(0.73-1.16)$ & 0.484 & $0.31(0.08-1.27)$ & 0.103 \\
\hline \multicolumn{5}{|l|}{$\mathrm{HER} 2^{\mathrm{a}}$} \\
\hline Negative & 1 & & Not included & \\
\hline Positive & $0.83(0.57-1.22)$ & 0.347 & & \\
\hline Borderline/Unknown & $1.20(0.87-1.66)$ & 0.266 & & \\
\hline \multicolumn{5}{|l|}{ Surgery } \\
\hline Breast-conserving surgery & 1 & & 1 & \\
\hline Mastectomy & $2.22(1.90-2.59)$ & $<0.001$ & $1.26(1.04-1.54)$ & 0.02 \\
\hline Others/Unknown & $7.05(5.77-8.62)$ & $<0.001$ & $6.57(5.04-8.55)$ & $<0.001$ \\
\hline \multicolumn{5}{|l|}{ Radiation therapy } \\
\hline No & 1 & & 1 & \\
\hline Yes & $0.54(0.47-0.62)$ & $<0.001$ & $0.92(0.77-1.10)$ & 0.351 \\
\hline Unknown & $0.50(0.24-1.05)$ & 0.067 & $0.54(0.25-1.17)$ & 0.12 \\
\hline \multicolumn{5}{|l|}{ Chemotherapy } \\
\hline No & 1 & & 1 & \\
\hline Yes & $0.89(0.77-1.03)$ & 0.116 & $0.67(0.55-0.80)$ & $<0.001$ \\
\hline Unknown & $0.72(0.53-0.99)$ & 0.043 & $0.61(0.43-0.85)$ & 0.004 \\
\hline \multicolumn{5}{|l|}{ Endocrine therapy } \\
\hline No & 1 & & 1 & \\
\hline Yes & $0.44(0.38-0.51)$ & $<0.001$ & $0.60(0.50-0.73)$ & $<0.001$ \\
\hline Unknown & $0.56(0.40-0.78)$ & $<0.001$ & $0.77(0.54-1.09)$ & 0.145 \\
\hline
\end{tabular}

HR Hazard ratio, $\mathrm{Cl}$ confidence interval

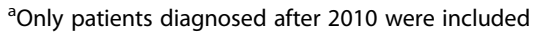

for IDC patients, but not for SCC patients. Despite of this, we still observed that the endocrine therapy significantly improves the OS in HR-positive IDC and SCC patients. Taken together, we suggested that endocrine therapy should remain as the standard treatment for HR-positive SCC patients. Ng et al. [5] studied the landscape of somatic genetic alterations of SCC and reported that TP53(78\%) and PI3KCA(44\%) are the most frequently mutated genes in SCC. They proposed that the mutation affecting genes might result in the Wnt and mTOR pathway activation. Future studies are warranted to investigate whether relevant pathway inhibitors could be used for SCC patients.
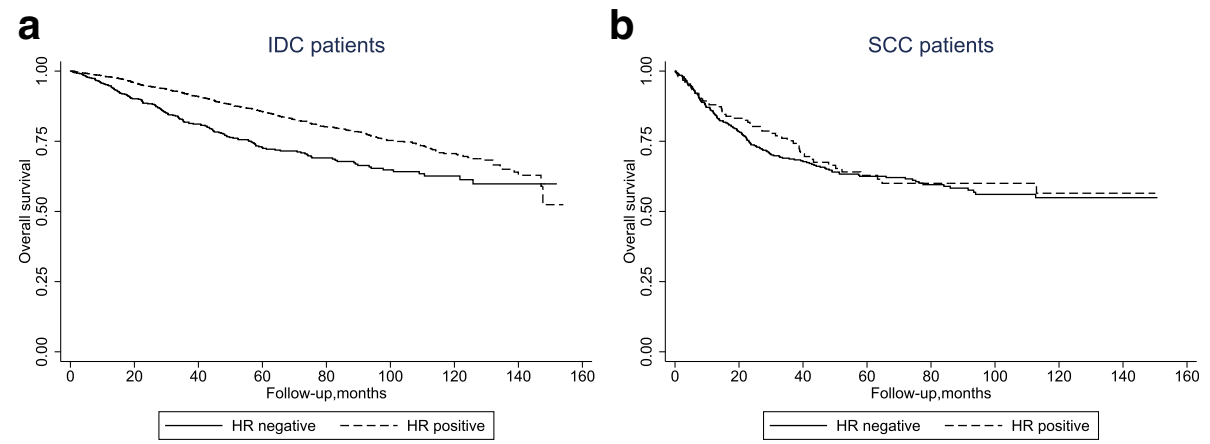

Fig. 1 Kaplan-Meier survival analysis stratified by HR status in (a) IDC and (b) SCC patients 

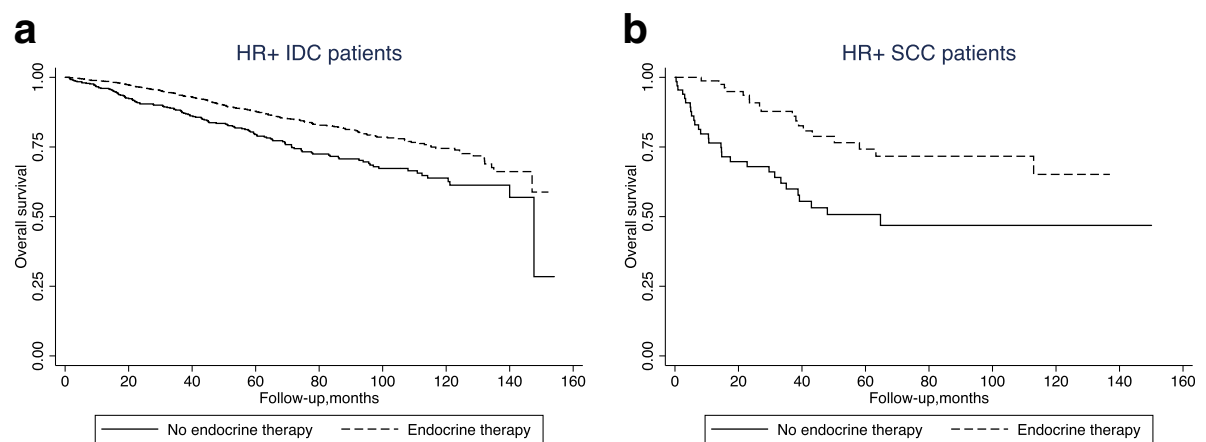

Fig. 2 Kaplan-Meier survival analysis stratified by endocrine therapy in (a) HR-positive IDC patients, and (b) HR-positive SCC patients

\section{SCC \& local therapy}

We assessed the influence of the SCC component on the local therapy. SCC patients had a slightly lower rate of BCS, when compared to IDC patients $(58.3 \%$ vs. $65.4 \%$, $P=0.048)$. The underlying reason could be that the SCC patients had larger tumor than IDC patients (T3-4: $23.1 \%$ vs. $4 \%$ ). Among patients with BCS, RT was used in 65.3 and $83.0 \%$ of the SCC and IDC patients, respectively. Currently, evidence that support the use of RT for SCC is lacking. Hennessy et al. [2] reported that 4 out of 19 SCC patients treated with RT had locoregional relapse within the irradiated field, suggesting that SCC might be radioresistant. Two studies [16, 17] reported no benefit of RT on OS, but the small sample sizes in these studies limited their statistical power. Using the SEER database, Wu et al. [18] reported that RT was significantly associated with improved OS but not cancer-specific survival, which is difficult to explain. Furthermore, they reported that RT was significantly associated with improved CSS in stage II SCC patients, but the analysis was not adjusted for ER, PR or HER2. Thus, the role of RT as an adjuvant local control therapy after surgery remains controversial.

\section{Limitations}

First, it is possible that the IDC patients may have a small proportion of SCC component area. Without pathological confirmation, grouping the cases into IDC, and SCC might not be always accurate. However, a detailed histopathology examination is impossible in mining large database, such as NCDB. The large sample size of this study population is able to compensate this limitation. Second, nonrandomized comparisons of treatment effects are prone to providing misleading estimations. One study [19] showed that the treatment effect of RT in breast cancer was over-estimated in observational data compared with randomized clinical trial data. This effect is reasonable as the "treatment-by-indication" bias can never be eliminated in observational data. Therefore, we did not estimate the survival benefit of chemotherapy, as patients with more advanced diseases are prone to receive chemotherapy. However, estimation of the survival benefit of endocrine therapy in HR-positive patients is less likely to be affected by the "treatment-by-indication" bias. HR-positive is the only indication for endocrine therapy. In addition, the decision to implement the endocrine therapy is less likely to be influenced by the comorbidity status. Thus, estimation of the survival benefit of endocrine therapy using observational data is reasonable. Due to the rarity of SCC of the breast, a prospective, randomized study for SCC cannot be realistically implemented. Third, the NCDB did not have information regarding trastuzumab therapy. Whether trastuzumab would be appropriate for HER2-positive SCC patients remains unclear. The lack of information regarding local relapse, metastatic relapse and cancer-specific survival is also one of the limitations. Fourth, there is a growing awareness of an association between SCC of the breast and implants. But the significance of the association is unclear due to the rarity of this situation [20-22]. The NCDB database does not have the information about the history of breast implants augmentation before the diagnosis of SCC, therefore limits our understanding about this issue.

\section{Conclusions}

In this study, we show that compared with IDC, SCC is associated with poorer clinicopathological outcomes. The treatment patterns differ between IDC and SCC. Radiotherapy after BCS is used less often for SCC (vs. IDC) patients. Chemotherapy is used more often for low-risk (HR+/HER2-, node-negative) SCC (vs. IDC) patients. Endocrine therapy is used less often in HRpositive SCC (vs. IDC) patients. In addition, SCC is less likely to response to chemotherapy, and is associated with worse clinical outcomes. Although the HR status is not prognostic in SCC patients, endocrine therapy is still associated with improved OS in HR-positive SCC patients. 


\section{Additional file}

Additional file 1: Figure S1. Kaplan-Meier survival analysis stratified by histology (IDC vs. SCC) and nodal status in a) HR-positive and b) HRnegative patients. (PDF $62 \mathrm{~kb}$ )

\section{Abbreviations}

BCS: Breast-conserving surgery; ER: Estrogen receptor; HR: Hormonal receptor; IDC: Infiltrating ductal carcinoma; LN: Lymph node; LVI: Lymphovascular invasion; NCDB: National cancer database; OS: Overall survival; PR: Progesterone receptor; RT: Radiation therapy; SCC: Squamous cell carcinoma

\section{Acknowledgements}

The NCDB is a joint project of the Commission on Cancer of the American College of Surgeons and the American Cancer Society. The data used in the study are derived from a de-identified NCDB file. The American College of Surgeons and the Commission on Cancer have not verified and are not responsible for the analytic or statistical methodology employed or the conclusions drawn from these data by the investigator. We appreciated Qian Ouyang for her assistance in the analysis of the study.

\section{Funding}

This study was supported by Guangdong Science and Technology Department (2017B030314026). The role of the funding body was to provide financial support for the cost of language editing service, as well as the publication charges.

\section{Availability of data and materials}

The data is available to all readers upon the readers' request.

\section{Authors' contributions}

LZ: Designed the study, collected and analyzed the data, wrote the manuscript, and approved it for final publication. KC: Designed the study, wrote and revised the manuscript, and approved it for final publication. Both of the authors agree to be accountable for all aspects of the work in ensuring that questions related to the accuracy or integrity of any part of the work are appropriately investigated and resolved.

\section{Ethics approval and consent to participate}

This study was an epidemiological study using de-identified data from the NCDB database. Therefore, consent for patient participation and study publication was not required. The study approval was waived by the ethical committee of Yale University and Sun Yat-sen Memorial Hospital.

\section{Consent for publication}

Not applicable.

\section{Competing interests}

The authors declare that they have no competing interests.

\section{Publisher's Note}

Springer Nature remains neutral with regard to jurisdictional claims in published maps and institutional affiliations.

\section{Author details}

${ }^{1}$ Guangdong Provincial Key Laboratory of Malignant Tumor Epigenetics and Gene Regulation, Sun Yat-Sen Memorial Hospital, Sun Yat-Sen University, Guangzhou, Guangdong, China. ${ }^{2}$ Department of Breast Surgery, Breast Tumor Center, Sun Yat-sen Memorial Hospital, Sun Yat-sen University, 107 Yanjiang West. Road, Guangzhou 510120, People's Republic of China. ${ }^{3}$ Department of Biostatistics, School of Public Health, Yale University, 300 George Suit 503, New Haven, CT 06511, USA.

Received: 7 August 2018 Accepted: 12 December 2018

Published online: 08 January 2019

\section{References}

1. Nayak A, Wu Y, Gilcrease MZ. Primary squamous cell carcinoma of the breast: predictors of locoregional recurrence and overall survival. Am J Surg Pathol. 2013;37(6):867-73.
2. Hennessy BT, Krishnamurthy S, Giordano S, Buchholz TA, Kau SW, Duan Z, Valero V, Hortobagyi GN. Squamous cell carcinoma of the breast. J Clin Oncol. 2005;23(31):7827-35.

3. Avigdor BE, Beierl K, Gocke CD, Zabransky DJ, Cravero K, Kyker-Snowman K, Button B, Chu D, Croessmann S, Cochran RL, et al. Whole-exome sequencing of Metaplastic breast carcinoma indicates Monoclonality with associated ductal carcinoma component. Clin Cancer Res. 2017;23(16):4875-84

4. Piscuoglio S, CKY N, Geyer FC, Burke KA, Cowell CF, Martelotto LG, Natrajan R, Popova T, Maher CA, Lim RS, et al. Genomic and transcriptomic heterogeneity in metaplastic carcinomas of the breast. NPJ Breast Cancer. 2017;3:48

5. Ng CKY, Piscuoglio S, Geyer FC, Burke KA, Pareja F, Eberle CA, Lim RS, Natrajan R, Riaz N, Mariani O, et al. The landscape of somatic genetic alterations in Metaplastic breast carcinomas. Clin Cancer Res. 2017;23(14): 3859-70.

6. Zhang X-M, Zhang B, Zang F, Zhao L, Yuan Z, Wang P. Clinical features and treatment of squamous cell carcinoma of the breast. Onco Targets Ther. 2016;9:3181-5. https://doi.org/10.2147/OTT.S95128. eCollection 2016.

7. Bilimoria KY, Stewart AK, Winchester DP, Ko CY. The National Cancer Data Base: a powerful initiative to improve cancer care in the United States. Ann Surg Oncol. 2008;15(3):683-90.

8. Behranwala KA, Nasiri N, Abdullah N, Trott PA, Gui GP. Squamous cell carcinoma of the breast: clinico-pathologic implications and outcome. Eur J Surg Oncol. 2003;29(4):386-9.

9. Yadav S, Yadav D, Zakalik D. Squamous cell carcinoma of the breast in the United States: incidence, demographics, tumor characteristics, and survival. Breast Cancer Res Treat. 2017;164(1):201-8.

10. Bhatt $L$, Fernando I. Primary squamous cell carcinoma of the breast: achieving long-term control with cisplatin-based chemotherapy. Clin Breast Cancer. 2009:9(3):187-8.

11. Dejager D, Redlich PN, Dayer AM, Davis HL, Komorowski RA. Primary squamous cell carcinoma of the breast: sensitivity to cisplatinum-based chemotherapy. J Surg Oncol. 1995;59(3):199-203.

12. Esophageal and Esophagogastric Junction Cancers. www.ncen.org. Accessed 4 July 2018

13. Head and Neck Cancers. www.nccn.org. Accessed 4 July 2018.

14. Nelson $\mathrm{K}$, Helmstaedter $\mathrm{V}$, Lage $\mathrm{H}$. The influence of tamoxifen on growth behavior and cell-cell adhesion in OSCC in vitro. Oral Oncol. 2007;43(7):720-7.

15. Sukocheva OA, Wee C, Ansar A, Hussey DJ, Watson DI. Effect of estrogen on growth and apoptosis in esophageal adenocarcinoma cells. Dis Esophagus. 2013:26(6):628-35

16. Liu J, Yu Y, Sun JY, He SS, Wang X, Yin J, Cao XC. Clinicopathologic characteristics and prognosis of primary squamous cell carcinoma of the breast. Breast Cancer Res Treat. 2015;149(1):133-40.

17. Wang J, Zhang X, He J, Yang M, Tang J, Li X, Tang H, Xie X. Co-expression of EGFR and CK5/6 in primary squamous cell carcinoma of the breast. Med Oncol. 2014;31(9):172.

18. Wu SG, Sun JY, Liu WM, Li FY, Lin HX, He ZY. Effect of postoperative radiotherapy for squamous cell cancer of the breast in a surveillance epidemiology and end results population-based study. Oncotarget. 2016; 7(9):10684-93.

19. Henson KE, Jagsi R, Cutter D, McGale P, Taylor C, Darby SC. Inferring the effects of Cancer treatment: divergent results from early breast Cancer Trialists' collaborative group meta-analyses of randomized trials and observational data from SEER registries. J Clin Oncol. 2016;34(8):803-9.

20. Buchanan PJ, Chopra VK, Walker KL, Rudolph R, Greco RJ. Primary squamous cell carcinoma arising from a breast implant capsule: a case report and review of the literature. Aesthet Surg J. 2018;38(7):97-102.

21. Olsen DL, Keeney GL, Chen B, Visscher DW, Carter JM. Breast implant capsule-associated squamous cell carcinoma: a report of 2 cases. Hum Pathol. 2017:67:94-100.

22. Zomerlei TA, Samarghandi A, Terando AM. Primary squamous cell carcinoma arising from a breast implant capsule. Plast Reconstr Surg Glob Open. 2015;3(12):e586. 